\title{
Novel Tie Method for the Fixation of a Brain Infusion Cannula in a Murine Model
}

\author{
Seog-Kyun Mun (D) and Munyoung Chang (D) \\ Department of Otorhinolaryngology-Head and Neck Surgery, Chung-Ang University College of Medicine, Seoul, Korea
}

동물 모델에서의 새로운 Brain Infusion Cannula 고정 방법

문석균 · 장문영

중앙대학교 의과대학 이비인후과학교실

\author{
Received March 18, 2021 \\ Revised April 1, 2021 \\ Accepted April 7, 2021 \\ Address for correspondence \\ Munyoung Chang, MD, $\mathrm{PhD}$ \\ Department of Otorhinolaryngology- \\ Head and Neck Surgery, \\ Chung-Ang University \\ College of Medicine, \\ 84 Heukseok-ro, Dongjak-gu, \\ Seoul 06974, Korea \\ Tel +82-2-6299-1765 \\ Fax +82-2-825-1765 \\ E-mail cadu01@cau.ac.kr
}

\begin{abstract}
Although brain infusion cannula is a good method to deliver compounds directly into the brain, fixation of the brain infusion cannula is essential for successful delivery. Dental cements and adhesive gel are the commonly used materials for fixation of the infusion cannula. However, these materials take time to harden and occasionally, fixation may fail. Therefore, we developed a novel method to fix the brain infusion cannula. Brain infusion cannulas were implanted into seven Wistar rats using the novel tie method. One, three, and seven days after the surgery, displacement of the brain infusion cannula and cerebrospinal fluid (CSF) leakage were evaluated in all the rats. None of the animals showed displacement of the brain infusion cannula or leakage of CSF at any point of time. In this study, we showed the successful results of the novel tie method for fixation of the brain infusion cannula, which needs no additional materials. It only requires a thread which is used for skin sutures.

Korean J Otorhinolaryngol-Head Neck Surg 2021;64(5):370-2

Key Words Brain · Cannula $\cdot$ Cerebrospinal fluid.
\end{abstract}

\section{Introduction}

In order to evaluate the effect of a drug on the brain, it must successfully reach the brain. Systemic drug administration is the most commonly used method of drug administration. To reach the brain, drugs administered systemically must cross the blood-brain barrier. However, many drugs do not successfully cross the blood-brain barrier. Therefore, systemic drug administration may be an inadequate way to determine the effects of drugs on the brain. Consequently, in many cases, a topical injection administered directly into the brain is the optimal way to generate reliable data.

A brain infusion cannula connected to a mini-osmotic pump

This is an Open Access article distributed under the terms of the Creative Commons Attribution Non-Commercial License (https://creativecommons.org/licenses/by-nc/4.0) which permits unrestricted non-commercial use, distribution, and reproduction in any medium, provided the original work is properly cited. may be a good delivery method. Several studies have used brain infusion cannula as a delivery method. ${ }^{1-6)}$ Fixation of the infusion cannula is mandatory for accurate delivery. Dental cements or adhesive gel have been used for fixation. However, these methods involve additional cost and time. Sometimes, they may also cause inflammation and the results of fixation may be unsatisfactory. Therefore, we developed a novel method to fix the brain infusion cannula, which requires no additional materials. It just needs the thread which is used for skin sutures.

\section{Methods}

This study was approved by the Institutional Animal Care and Use Committee of Chung-Ang University (2016-00086).

A total of seven male Wistar rats (7-weeks old, 200-250 g) 
were used. All animals were acclimatized to the laboratory conditions for 1 week before the start of the experiment. They were housed in a temperature- and humidity-controlled room with a 12 hour contrast cycle with free access to food and water.

\section{Surgical procedure}

The animals were anesthetized by intraperitoneal administration of ketamine hydrochloride $(100 \mathrm{mg} / \mathrm{kg}$; Ketamine, Yuhan, Seoul, Korea) mixed with xylazine (10 mg/kg; Rompun, Bayer-Korea, Seoul, Korea). The surgical procedure is shown in Fig. 1. First, the hair on the skull was shaved. After local anesthesia with $1 \%$ lidocaine hydrochloride, a curved incision was made on the skull. The skin flap was elevated and periosteum on the skull was exposed. Then, the periosteum was harvested from the skull and bregma was identified. A burr hole was made in the skull (AP: -0.3, L: 1.2, V: 4.5), according to the atlas of Paxinos and Watson (2006) to approach the right cerebral lateral ventricle. The temporalis muscles were sutured bilaterally using a non-absorbable monofilament [e.g., Blue Nylon 5-0 (Ailee, Busan, Korea)] but tie was not made. Harvested periosteum was place around the burr hole. A brain infusion cannula connected to a mini-osmotic pump was filled with $0.4 \%$ carmine in saline and implanted through the burr hole. Harvested periosteum was lo- cated beneath the brain infusion cannula. The non-absorbable monofilament was positioned on the brain infusion cannula, following which a tie was made tightly to allow no room between the brain infusion cannula, periosteum, and skull. Finally, the skin flap was repositioned and sutured.

\section{Evaluation of displacement of the brain infusion cannula and cerebrospinal fluid leakage}

One day after the surgery, all animals were anesthetized as described above. Skin flap on the skull was elevated again and position of the brain infusion cannula was checked. The area around the brain infusion cannula was inspected with the aid of a microscope for the appearance of fluid collection and blue pigmentation. Three and seven days after the surgery, the same procedure was repeated to evaluate the displacement of the brain infusion cannula and cerebrospinal fluid (CSF) leakage.

\section{Results}

No animal died during the procedure. One, three, and seven days after the surgery, displacement of the brain infusion cannula and CSF leakage were evaluated in the seven rats. There were no animals showing a change in the location of the brain infusion cannula or CSF leakage (Fig. 2).
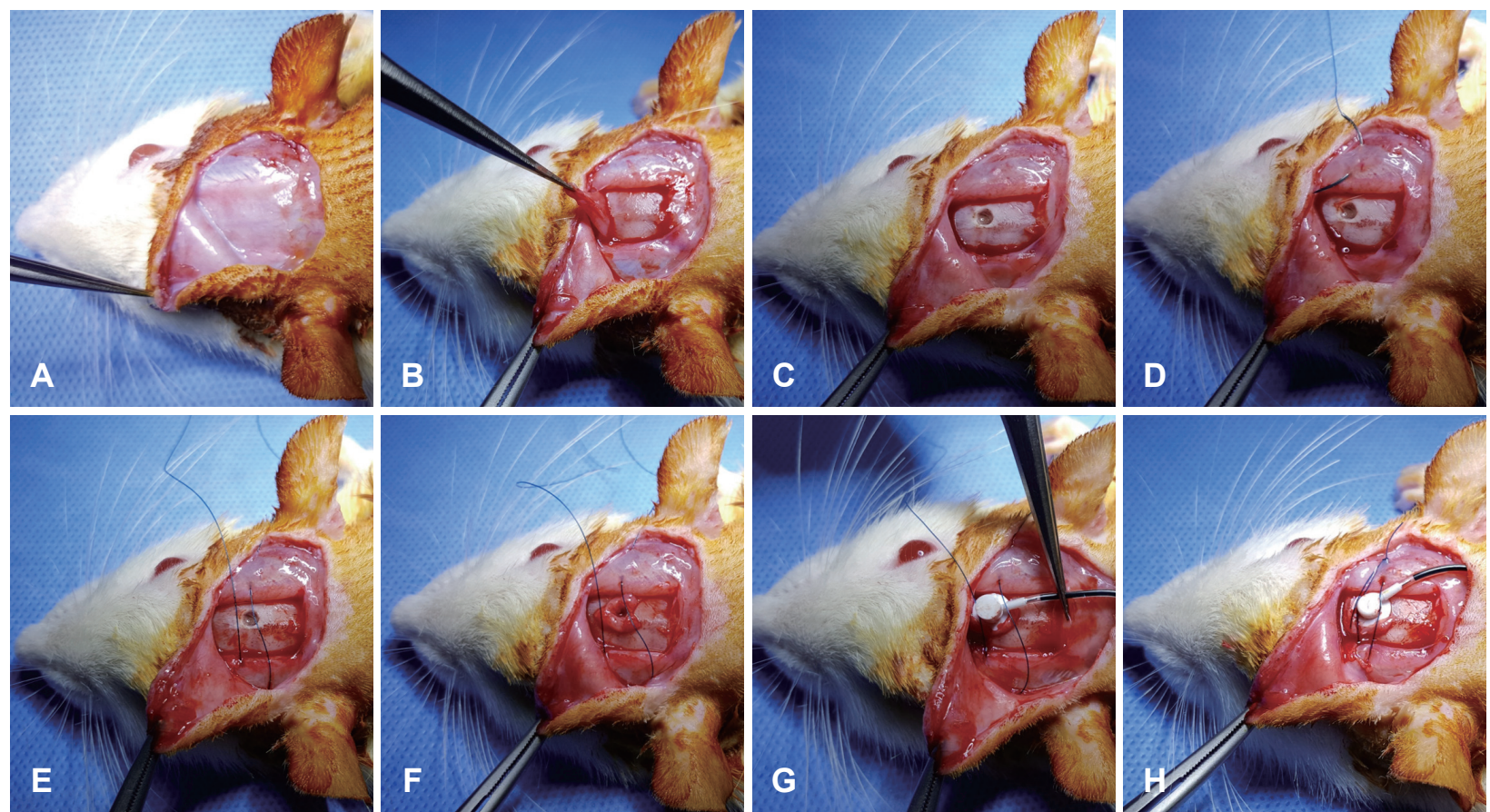

Fig. 1. Surgical procedure of the novel tie method. Elevation of the skin flap (A). Harvesting of the periosteum (B). Making a burr hole (C). Suturing temporalis muscles at both sides $(\mathrm{D}, \mathrm{E})$. Placement of the harvested periosteum around the burr hole $(F)$. Implantation of the brain infusion cannula on the harvested periosteum (G). Making a tight tie to prevent room between the brain infusion cannula, periosteum, and skull $(\mathrm{H})$. 


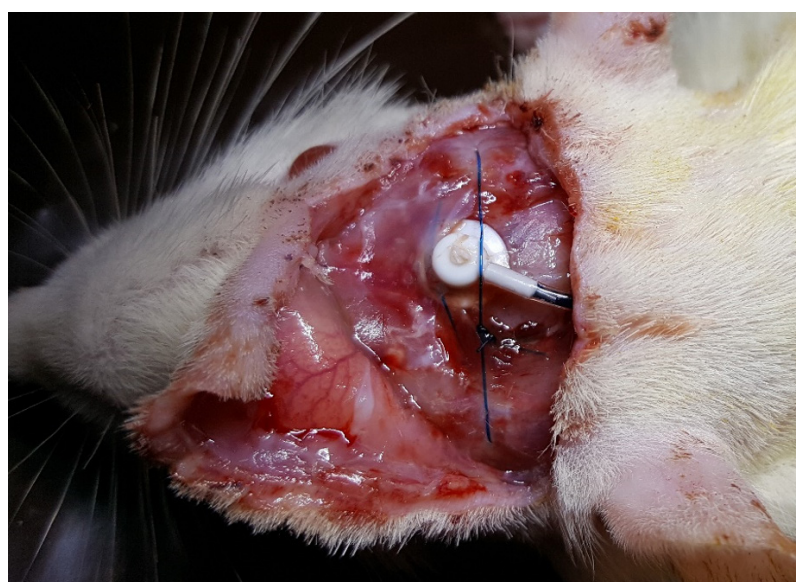

Fig. 2. State of the brain infusion cannula three days after the surgery. There was no displacement of the brain infusion cannula or cerebrospinal fluid leakage.

Although brain infusion cannula is a good method to deliver compounds directly into the brain, fixation of the brain infusion cannula is essential for successful delivery. Failure of fixation may cause not only failure of delivery of the compounds but also CSF leakage. Dental cements and adhesive gel are the commonly used materials for the fixation of infusion cannula. However, since these materials take time to harden, the cannula need to be kept dry during this time for successful fixation. Thus, these methods require not only additional time but also cost more. Moreover, fixation may fail occasionally. Consequently, we developed a novel method, which needs no additional materials. The fixation requires only the thread used for skin sutures. Furthermore, this method does not need a dry field and there is no need to wait until it hardens. Therefore, we think that this method will help in making experiments that use brain infusion cannula more convenient and faster.

\section{Acknowledgments}

This work was supported by the National Research Foundation of Korea (NRF) grant funded by the Korea government (Ministry of Science and ICT) (No. NRF-2016R1C1B2007131 to MC).

\section{Author Contribution}

Conceptualization: Munyoung Chang. Data curation: Munyoung Chang. Formal analysis: Munyoung Chang, Seog-Kyun Mun. Funding acquisition: Munyoung Chang. Methodology: Munyoung Chang. Project administration: Munyoung Chang, Seog-Kyun Mun. Visualization: Munyoung Chang, Seog-Kyun Mun. Writing-original draft: Munyoung Chang, Seog-Kyun Mun. Writing-review \& editing: Munyoung Chang, Seog-Kyun Mun.

\section{ORCIDs}

Munyoung Chang https://orcid.org/0000-0003-0136-3893

Seog-Kyun Mun https://orcid.org/0000-0001-8624-2964

\section{REFERENCES}

1) Ahl M, Avdic U, Skoug C, Ali I, Chugh D, Johansson UE, et al. Immune response in the eye following epileptic seizures. J Neuroinflammation 2016;13(1):155.

2) Chang M, Kim HJ, Mook-Jung I, Oh SH. Hearing loss as a risk factor for cognitive impairment and loss of synapses in the hippocampus. Behav Brain Res 2019;372:112069.

3) Chang MY, Park S, Choi JJ, Kim YK, Suh MW, Lee JH, et al. MicroRNAs 218a-5p, 219a-5p, and 221-3p regulate vestibular compensation. Sci Rep 2017;7(1):8701.

4) de Kloet AD, Pitra S, Wang L, Hiller H, Pioquinto DJ, Smith JA, et al. Angiotensin type-2 receptors influence the activity of vasopressin neurons in the paraventricular nucleus of the hypothalamus in male mice. Endocrinology 2016;157(8):3167-80.

5) Perianes-Cachero A, Canelles S, Aguado-Llera D, Frago LM, ToledoLobo MV, Carrera I, et al. Reduction in A $\beta$-induced cell death in the hippocampus of $17 \beta$-estradiol-treated female rats is associated with an increase in IGF-I signaling and somatostatinergic tone. J Neurochem 2015;135(6):1257-71.

6) Tran TT, Srivareerat M, Alkadhi KA. Chronic psychosocial stress triggers cognitive impairment in a novel at-risk model of Alzheimer's disease. Neurobiol Dis 2010;37(3):756-63. 